\title{
Incidence of Transient Congenital Hypothyroidism due to Maternal Thyrotropin Receptor-Blocking Antibodies in Over One Million Babies*
}

\author{
ROSALIND S. BROWN, RONALD L. BELLISARIO, DIEGO BOTERO, \\ LAWRENCE FOURNIER, CYRIL A. L. ABRAMS, MARILYN L. COWGER, \\ RALPH DAVID, PAVEL FORT, AND ROBERT A. RICHMAN \\ Departments of Pediatrics (R.S.B., D.B.) and Nuclear Medicine (L.F.), University of Massachusetts \\ Medical Center, Worcester, Massachusetts 01655; Wadsworth Center for Laboratories and Research \\ (R.L.B.), Albany, New York 12201; and Children's Hospital at Albany Medical Center (M.L.C.), \\ Albany, New York 12208; Schneider Children's Hospital (C.A.L.A.), New York, New York 10042; the \\ Department of Pediatrics, New York University Medical Center (R.D.), New York, New York 10016; \\ North Shore University Hospital-Cornell Medical Center (P.F.), Manhasset, New York 11030; and \\ State University of New York Health Science Center (R.A.R.), Syracuse, New York 13210
}

\begin{abstract}
To determine the incidence of transient congenital hypothyroidism due to TSH receptor-blocking antibodies, we screened dried blood specimens obtained from 788 neonates identified as having possible congenital hypothyroidism (from a total population of $1,614,166$ babies) and 121 controls. A RRA was used. The potency of blood spot TSH binding inhibitory activity was compared with the severity of congenital hypothyroidism to assess the possible etiological relationship. Maternal serum was studied to confirm the presence of blocking antibodies by both RRA and bioassay.

Blood spots obtained from 9 infants contained potent TSH receptorblocking activity. Samples from 2 additional babies, studied because of clinical suspicion of the disease, were also positive. Long term outcome was known in 8 of the 11 babies, and all had transient
\end{abstract}

disease. Neonates with TSH receptor-blocking activity greater than $132 \mathrm{U} / \mathrm{L}$ had a significantly lower $\mathrm{T}_{4}$ level $(P<0.05)$ and higher TSH $(P<0.005)$ than those in whom TSH binding-inhibitory activity was less than $132 \mathrm{U} / \mathrm{L}$. All 9 mothers had autoimmune thyrnid disease, and 3 had more than 1 affected child. Potent blocking activity was present in 7 maternal serum samples as long as $7 \mathrm{yr}$ after the births of their affected babies.

We conclude that measurement of TSH binding-inhibitory activity in dried neonatal blood specimens is a simple and effective method to predict the occurrence of transient congenital hypothyroidism. The incidence of this disorder in North America is 1 in 180,000 normal infants, or approximately $2 \%$ of babies with congenital hypothyroidism. (J Clin Endocrinol Metab 81: 1147-1151, 1996)
C ONGENITAL hypothyroidism occurs in 1 in 4000 newborn babies and is one of the most frequent preventable causes of mental retardation (1). Although the majority of affected infants have a defect in thyroid gland development or thyroid hormone synthesis and will, therefore, require lifelong thyroid hormone replacement (2), in approximately $10 \%$ of babies detected by newborn screening, the abnormality in thyroid function will be transient (1). Recent interest has focused on the possible etiological role in some of these transient cases of maternal TSH receptor-blocking antibodies. Although difficult to distinguish at birth from those with the more common thyroid gland dysgenesis, affected infants differ from the latter in a number of important ways (3-5). They do not require lifelong therapy, results of thyroid imaging may be misleading in them, and there is a high recurrence rate in subsequent offspring due to the tendency of these antibodies to persist for many years in the

Received July 27, 1995. Revision received Seplember 14, 1995. Accepted September 21, 1995.

Address all correspondence and requests for reprints to: Dr. Rosalind Brown, Department of Pediatrics, University of Massachusetts Medical Center, Worcester, Massachusetts 01655.

* This work was supported in part by grants from Boots Pharmaceuticals, Inc., and the March of Dimes (6-492). maternal circulation (3-5). Furthermore, others have suggested recently that the intellectual outcome of babies with maternal blocking antibody-induced congenital hypothyroidism may be less favorable than that of babies with a permanent abnormality of the thyroid gland, especially if unrecognized maternal hypothyroidism was present in utero (6).

The incidence of transient congenital hypothyroidism secondary to maternal TSH receptor-blocking antibodies is unknown, and most information derived about this syndrome to date has been obtained from isolated case reports $(3-5,7)$. In the present study, we have taken advantage of the recent observation that affected babies can be identified by evaluation of $\left[{ }^{125} \mathrm{I}\right] \mathrm{TSH}$ binding inhibitory activity in dried neonatal blood specimens obtained for routine screening purposes (8). We have employed this technique to evaluate the incidence of this disorder in more than 1.6 million babies born in New York State over a 6-yr period and have analyzed the clinical and immunological data in a total of 9 babies so discovered as well as in their mothers. Data from 2 additional infants in whom the diagnosis was suspected clinically were evaluated similarly. We also sought to establish whether an etiological relationship was present by relating the potency of the blocking antibodies to the severity of congenital hypothyroidism. 


\section{Subjects and Methods}

\section{Study population}

A total of 899 dried blood specimens were obtained from 788 newborn infants in whom the screening levels of $\mathrm{T}_{4}$ were less than the tenth percentile for the assay and whose TSH concentrations were equal to or greater than $40 \mathrm{U} / \mathrm{L}$; infants who had an initial diagnosis of congenital hypothyroidism reported to the New York State Newborn Screening Program were also studied. These infants were selected from among $1,614,166$ babies screened for congenital hypothyroidism in New York State over the 6-yr period from 1984-1989. Blood spots from 121 normal or $\mathrm{T}_{4}$-binding globulin-deficient babies screened during the same period served as control specimens. The results with 465 test specimens and 88 controls obtained between 1987-1988 were reported in a previous pilot study (8). Dried blood specimens from an additional 2 babies were studied because of suspicion of the discase and are included in the clinical analysis. Blood spots were stored desiccated at $-20 \mathrm{C}$ before use and were studied without knowledge of the diagnosis. The study was approved by the University of Massachusetts Medical Center Committee for the Protection of Human Subjects in Research.

\section{Methods}

Dried blood specimens were eluted overnight in either 50\% Coon's F-12 medium or $10 \mathrm{mmol} / \mathrm{L}$ Tris- $\mathrm{HCl}$, $\mathrm{pH} 7.5$, containing $50 \mathrm{mmol} / \mathrm{L}$ $\mathrm{NaCl}$; both solutions gave equivalent results. The presence of TSH receptor-blocking activity was estimated in duplicate by evaluation of ${ }^{125}$ I]TSH binding inhibition to solubilized porcine receptor by the method of Southgate et al. (9) using either materials we prepared (8) (part 1) or a commercial kit (Kalibre, Kronus, Dana Point, CA; part 2). In part 1, blocking activity was expressed as the percent TSH binding inhibition according to the formula ( $1-\left[{ }^{125}\right.$ I]bovine TSH binding in the presence of test IgG/1 [ $\left.{ }^{125} \mathrm{I}\right]$ bovine TSH binding in the presence of normal IgG) $\times 100$. In part 2 , results were expressed as the TSH receptor antibody (TRAb) concentration in units per $L$ by comparison with a standard curve. A value greater than 2 so above the mean for normal infants was considered abnormal. We repeated the measurement if the level of blocking activity was greater than $1.5 \mathrm{sD}$ above the normal mean. Only spots with significant blocking activity in at least two assays were considered positive. After a positive spot was confirmed, clinical information was sought and, if not performed previously, a blood sample was obtained from the mother for measurement of blocking antibodies.

To ascertain whether the maternal serum blocked the bioactivity of $\mathrm{TSH}$ as well as its binding, we measured the inhibition of TSH-induced stimulation of adenyl cyclase using recombinant human TSH receptor that had been stably transfected into Chinese hamster ovary cells; the latter were a generous gift from Dr. Lconard Kohn, NIH. Cells were grown overnight to confluence in Costar 24-well plates containing Coon's Modified F-12 buffer and 0.2\% FBS. Before assay, cells were washed twice with hypotonic HBSS containing $0.5 \mathrm{mmol} / \mathrm{L}$ 3-isobutylL-methyl-xanthine (10) and incubated for $1 \mathrm{~h}$ at $37 \mathrm{C}$ in the same buffer plus $100 \mathrm{mU} / \mathrm{L}$ recombinant human TSH (Genzyme Corp., Cambridge, MA). cAMP released into the medium was measured by RIA (Incstar Corp., Stillwater, MN).

Thyroid peroxidase (TPO) antibodies were measured by RIA (Kronus). Values greater than $1 \mathrm{U} / \mathrm{L}$ were considered abnormal. In one case in which data obtained previously was used for the analysis, the assay in current clinical use was employed.

\section{Statistics}

The significance of the difference between groups was evaluated by Student's $t$ test. $P<0.05$ was considered significant.

\section{Results}

Dried blood specimens from a total of 11 neonates were found to contain significant TSH binding inhibitory activity. Nine of these were obtained from the screening portion of the study; 2 additional babies were identified because of clinical suspicion of the disorder. Three of the former cases have been reported previously (8). In all instances, blocking activity was extremely potent, being at least 3 SD above the mean for normal newborns. In 7 of the cases, the level was more than $4 \mathrm{SD}$, and in 3 , it was greater than $20 \mathrm{SD}$.

The available clinical data for the 11 infants are presented in Table 1 . All 8 babies in whom follow-up information was available had transient disease. Those babies with the most potent TSH binding inhibitory activity had the most severe hypothyroidism, as determined by comparison with results of thyroid function tests performed in the same spots at the time of newborn thyroid screening. Furthermore, in this group of babies, the antibodies were sufficiently potent to block TSH-induced uptake of radioactive iodine on thyroid scan, leading to the misdiagnosis of thyroid agenesis. In part 2, a sufficient number of babies was studied to permit statistical analysis. As demonstrated in Fig. 1, the 3 infants with the highest TSH binding inhibitory activity $(>132 \mathrm{U} / \mathrm{L})$ had a significantly lower mean $\mathrm{T}_{4}$ concentration on neonatal screening (mean $\pm \mathrm{sD}, 47 \pm 21 \mathrm{vs}$. $93 \pm 39 \mathrm{nmol} / \mathrm{L} ; P<0.05)$ and a significantly higher TSH level $(>200$ vs. $85 \pm 48 \mathrm{mU} / \mathrm{L} ; P<0.05)$ than those with TSH binding inhibitory activity less than $132 \mathrm{U} / \mathrm{L}$.

TABLE 1. Clinical and laboratory data of 11 infants with transient congenital hypothyroidism due to maternal TSH receptor-blocking antibodies

\begin{tabular}{|c|c|c|c|c|c|}
\hline Spot No. & Spot TBI/TRAb $(\%, \mathrm{U} / \mathrm{L})^{\alpha}$ & Spot $T_{4}(\mathrm{nmol} / \mathrm{L})$ & Spot TSH (mU/L) & Clinical course & Thyroid scan \\
\hline \multicolumn{6}{|l|}{ Part 1} \\
\hline 157 & 61 & 84 & $>200$ & Unknown & No uptake \\
\hline 394 & 55 & 116 & $>200$ & Transient & Normal \\
\hline 320 & 51 & 116 & 75 & Transient & Not done \\
\hline \multicolumn{6}{|l|}{ Part 2} \\
\hline 747 & $>132$ & 39 & $>200$ & Transient & No uptake \\
\hline 574 & $>132$ & 71 & $>200$ & Transient & No uptake \\
\hline A188 & $>132$ & $<31$ & $>200$ & Transient & No uptake \\
\hline A118 & 57 & $<31$ & 150 & Unknown & Not done \\
\hline A 135 & 61 & 84 & 120 & Transient & Normal \\
\hline 784 & 87 & 103 & 120 & Transient & Normal \\
\hline 1002 & 58 & 84 & 75 & Transient & Not done \\
\hline A186 & 72 & 148 & 45 & Still on Rx. & Not done \\
\hline Normal & $<23 /<37$ & $103-309$ & $<20$ & & \\
\hline
\end{tabular}

${ }^{a}$ In part 1, blocking activity was calculated according to the formula $\left(1-\left[{ }^{125} \mathrm{I}\right]-\mathrm{bTSH}\right.$ binding in the presence of test IgG/1 - $\left[{ }^{125} \mathrm{I}\right]-\mathrm{bTSH}$ binding in the prescnec of normal IgG) $\times 100$ and expressed as percent TSH binding inhibition, TBI. In part 2 , the TSH receptor antibody (TRAb) concentration was expressed as units per L by comparison with a standard curve, according to the instructions of the manufacturer. 
FIG. 1. Relationship between TSH receptor-blocking antibodies and neonatal thyroid function. Infants with the most potent blocking activity (TRAb, $>132 \mathrm{U} / \mathrm{L}$; had a significantly lower $\mathrm{T}_{4}$ and higher TSH when measured at the time of neonatal screening on the same blood spots than did those with less potent blocking activity (TRAb, $<132 \mathrm{U} / \mathrm{L} ; \square)$.
$\mathrm{T} 4$

$(\mathrm{nmol} / \mathrm{L})$

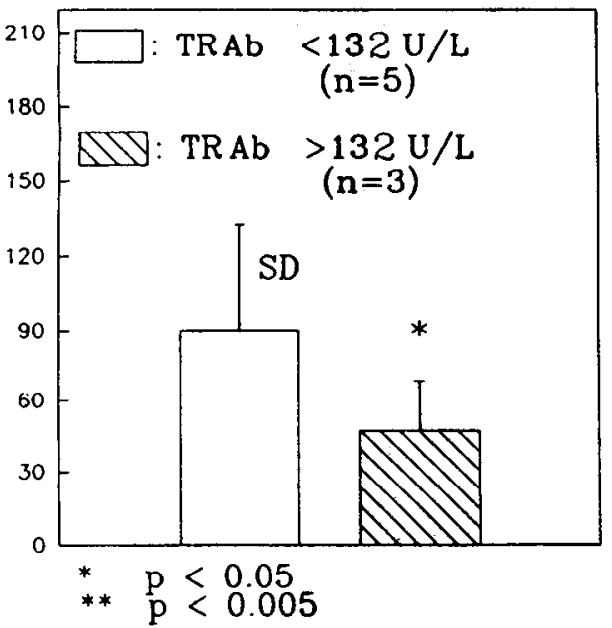

TSH

$(\mathrm{mU} / \mathrm{L})$

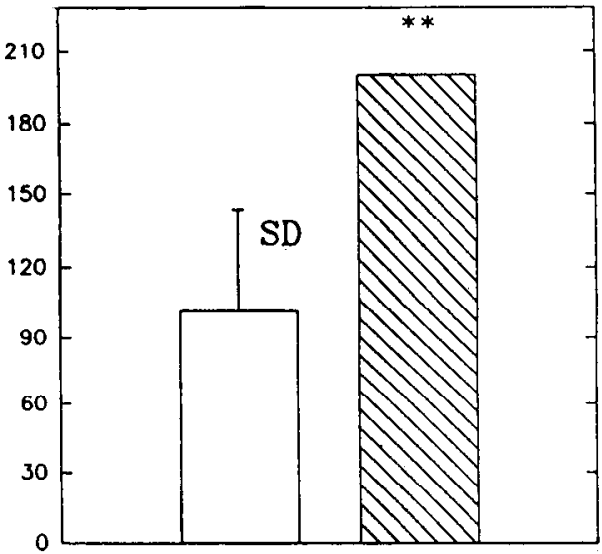

Clinical information in the mothers is presented in Table 2. The 11 babies were born to 9 mothers, all of whom had been diagnosed as having hypothyroidism and were being treated with thyroid hormone. Three of the mothers had been treated initially for Graves' disease. None of the 4 mothers examined had a palpable goiter. Two mothers had more than 1 affected child, and 1 has had, in turn, a normal infant, one with hyperthyroidism, and one with hypothyroidism (11). The presence of TRAb was confirmed around the time of delivery in 3 of the 9 mothers. Blood was obtained in 5 mothers $2.3-7.6$ yr after birth (or, in mothers 320 and A188, after the birth of their first affected infants). Potent $\left[{ }^{125} I\right] T S H$ binding inhibitory activity persisted in all sera at a dilution of 1:40 to 1:160 (Fig. 2). Similarly, all sera studied contained potent in vitro blocking activity, as measured by inhibition of TSH-induced stimulation of cAMP, which was detectable in serum at a dilution of 1:50 (Fig. 2). In comparison, the stimulatory effect of most Graves' IgG cannot be demonstrated using unextracted serum in this assay system, but requires prior $\operatorname{Ig} G$ purification.
There was no apparent loss of blocking activity for at least $6 \mathrm{yr}$; two positive spots were identified in each of the years 1984,1985 , and 1986, and one in 1989. Furthermore, no significant difference in TSH binding inhibitory activity was observed between spots from control babies with $\mathrm{T}_{4}$-binding globulin deficiency from 1984 vs. 1989 (13.0 \pm 3.6 vs. $14.3 \pm$ $3.9 \mathrm{U} / \mathrm{L} ; P=\mathrm{NS}$ ).

In contrast to the striking TSH receptor-blocking activity, TPO antibody concentrations were variable and, in fact, were of only borderline significance in two patients.

\section{Discussion}

In this study, we screened neonatal blood spots for TSH binding inhibitory activity to estimate the incidence of transient blocking antibody-induced congenital hypothyroidism in North America and elucidate whether the potency of the blocking antibodies is related to the degree of neonatal hypothyroidism. To attempt to identify all such affected infants,

TABLE 2. Clinical and laboratory data of mothers of infants with transient congenital hypothyroidism

\begin{tabular}{|c|c|c|c|c|}
\hline Spot No. & Clinical history & Serum & TBITRAb $(\%, \mathrm{U} / \mathrm{L})$ & Serum TPO Abs \\
\hline 157 & Hypothyroid on Rx. & & $85.5^{a}$ & $376^{b}$ \\
\hline 394 & Hypothyroid S/P GD on Rx, MGM hypothyroid & & $82.8^{a}$ & $17.0^{c}$ \\
\hline 320 & Hypothyroid on Rx. MGGM, + maternal aunt with GD & & $>132$ & $1.3^{c}$ \\
\hline 747 & Hypothyroid on Rx for $9 \mathrm{yr}$ & & Not done & Not done \\
\hline 574 & Hypothyroid S/P GD on Rx & & $90.0^{a}$ & Not done \\
\hline A188 & Hypothyroid on $\mathrm{Rx}$ for $7 \mathrm{yr}, 2$ nd infant with $\mathrm{CH}, \mathrm{MGM}$ with GD & & $>132$ & $28.0^{c}$ \\
\hline A118 & Hypothyroid on Rx, GM + aunt with "thyroid problem" & & Not done & Not done \\
\hline A135 & Hypothyroid S/P Graves; on Rx & & $>132$ & $1.5^{\mathrm{c}}$ \\
\hline 784 & Hypothyroid on $\mathrm{Rx}$ for $2 \mathrm{yr}$ & & $>132$ & $5.8^{c}$ \\
\hline 1002 & Same as no. 320 & & & \\
\hline A186 & Same as no. 320 & & & \\
\hline Normal & & & $<15 /$ & \\
\hline
\end{tabular}

TRT, TSH hinding inhibition; TRAb, TSH receptor antibody; Rx, treatment; S/P, status post; GD, Graves' disease; MGM, maternal grandmother; GM, grandmother; MGGM, maternal great grandmother; $\mathrm{CH}$, congenital hypothyroidism.

${ }^{a}$ Performed at Nichols Institute (San Juan Capistrano, CA).

${ }^{b}$ Performed elsewhere, details not available (normal, <25).

${ }^{c}$ Performed in this laboratory, as described in Materials and Methods (normal, <1 U/L). 


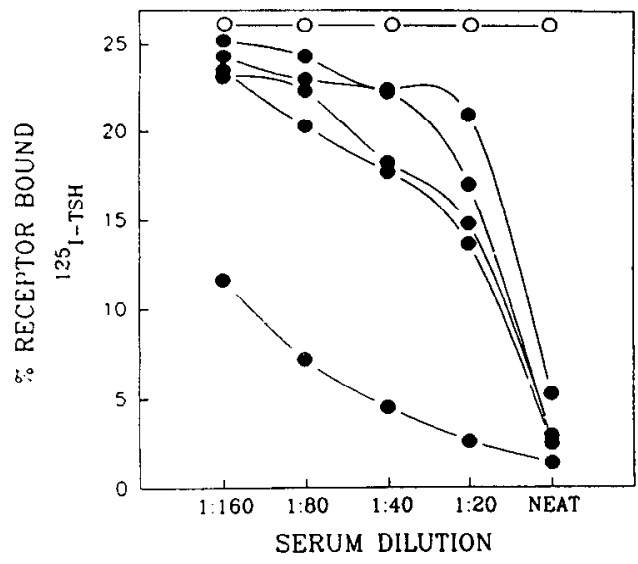

FIG. 2. 'I'SH receptor-blocking activity of maternal serum. Maternal serum () obtained 2.3-7.6 yr after delivery of the affected infant still contained potent blocking activity whether measured by RRA (left) or hioassay (right). See text for details. $O$, Normal nonpregnant women.

\section{Binding Assay}

2. Functional Assay

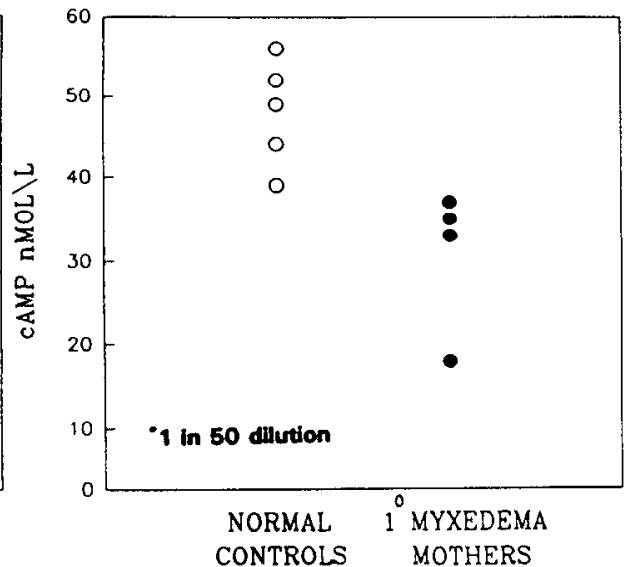

CONTROLS MOTHERS we studied dried blood specimens obtained not only from babies with confirmed congenital hypothyroidism, but from any baby whose initial $\mathrm{T}_{4}$ was in the lowest $10 \%$ for the assay or whose TSH was $40 \mathrm{U} / \mathrm{L}$ or more. Nine babies from a total population of 1,614,166 were found to have TSH receptor blocking antibody-induced congenital hypothyroidism, giving an incidence of about 1 in 180,000. As the incidence of congenital hypothyroidism in North American has been estimated to be 1 in 4,000 , this suggests that 1 in 45 infants, or approximately $2 \%$ of cases of congenital hypothyroidism, are caused by maternal TSH receptor-blocking antibodies.

In all cases, the finding of a blood spot with significant TSH binding inhibitory activity correctly identified a baby with transient congenital hypothyroidism. Furthermore, potent TSH receptor-blocking activity was confirmed in all maternal sera studied. In fact, dose-response studies revealed that the inhibitory activity in maternal serum, which was evaluated as long as $7 \mathrm{yr}$ after the baby's birth, was sufficiently potent that it could be demonstrated at a 1:40 to 1:200 dilution of serum in the RRA and at a 1:50 dilution in the bioassay employed. Although the underlying immunological mechanisms remain unclear, the persistence of these blocking antibodies in some patients for many years explains the tendency for a mother to have multiple affected offspring. The tendency for others to switch from secreting a preponderance of stimulatory to blocking antibodies complicated in some cases by decreased thyroid gland responsivity is the basis for the change from hyperthyroidism to hypothyroidism $(11,12)$. Hypothyroidism can also precede hyperthyroidism (13). In rare instances, a more complicated neonatal picture can result due to the coexistence of blocking antibodies and stimulatory ones. In this case, a delayed onset of neonatal Graves' disease occurs because of the progressive dilution of the more potent inhibitory effect over time (14). In the present study, two mothers had more than one affected infant, and one patient has had successively a normal, a hyperthyroid, and a hypothyroid baby. For these reasons, genetic counselling is of utmost importance to alert mothers of the high risk of recurrence and to ensure prompt evaluation (and treatment) of all subsequent offspring.

Babies with the most potent TSH binding inhibitory ac- tivity had the most profound hypothyroidism, as delermined by thyroid function testing on the same dried blood specimens and had the most severe inhibition of radioisotopic uptake on thyroid scan. These findings as well as the transient course in all babies identified provide strong evidence that the maternal blocking antibodies were of etiological importance in the hypothyroidism observed. This relationship between blocking activity and the severity of congenital hypothyroidism in the offspring has been reported previously in maternal serum $(15,16)$. Maternal sera also inhibited recombinant human TSH-induced adenyl cyclase stimulation of recombinant human TSH receptor, verifying that the blocking antibodies inhibited the action of TSH on the human receptor in vitro.

Despite being exposed to potent ISH receptor-blocking activity in utero, these infants did not develop any long term abnormality in thyroid function. This is consistent with the fact that TSH receptor-blocking antibodies, like other IgG, do not cross the placenta until 16 weeks (17) and, therefore, could not play a role in early thyroid embryogenesis.

All mothers, like those identified in previous studies ( $3-5$, 7) had underlying autoimmune thyroid disease. All were receiving thyroid replacement because of hypothyroidism, and in three, this had been preceded by a hyperthyroid phase. This suggests that only babies born to mothers with underlying autoimmune thyroid disease are at risk for the development of blocking antibody-induced congenital hypothyroidism. However, severe hypothyroidism in some mothers was not diagnosed until they were postpartum, and their babies were found to have congenital hypothyroidism due to TSH receptor-blocking antibodies (18). Also, it should be emphasized that TPO antibodies, although detectable in all mothers, were of no use in predicting the development of transient disease in the neonate.

In summary, we estimate the incidence of TSH receptorblocking antibody-induced congenital hypothyroidism to be 1 in 180,000 , or about $2 \%$ of all cases of congenital hypothyroidism. Whether routine screening for the presence of maternal TSH receptor-blocking antibodies should be performed in all babies with congenital hypothyroidism and whether mothers or babies should be studied will 
depend on further information about the prevalence of these antibodies in pregnant women, a careful cost analysis, and whether decreased intellectual ability occurs in some of these infants despite adequate postnatal therapy. In the meantime, the diagnosis should be suspected whenever congenital hypothyroidism is diagnosed in the baby of a mother with hypothyroidism due to autoimmune thyroid disease, particularly if previous offspring have had congenital hypothyroidism. Similarly, any baby with eutopic thyroid tissue evident on thyroid ultrasound should be studied regardless of the thyroid scan result.

\section{References}

1. Fisher DA, Dussault JH, Foley Jr TP, et al. 1979 Screening for congenital hypothyroidism: Results of screening one million North American infants. J Pediatr. 94:700-705.

2. New England Congenital Hypothyroidism Collaborative. 1984 Characteristics of infantile hypothyroidism discovered on neonatal screening. J Pediatr. 104:539-544.

3. Matsuura N, Yamada Y, Nohara Y, et al. 1980 Familial neonatal transient hypothyroidism due to maternal TSH-binding inhibitor immunoglobulins. N Engl J Med. 303:738-741.

4. Connors MH, Styne DM. 1986 Transient neonatal "athyreosis" resulting from thyrotropin-binding inhibitory immunoglobulins. Pediatrics. 78:287-290.

5. Francis G, Riley W. 1987 Congenital familial transient hypothyroidism secondary to transplacental thyrotropin-blocking autoantibodies. Am J Dis Child. 141:1081-1083.

6. Matsuura N, Konishi J, Transient Hypothyroidism Study Group in Japan. 1990 Transient hypothyroidism in infants born to mothers with chronic thyroiditis-a nationwide study of twenty-three cases. Endocrinol Ipn. 37:369-379.
7. Goldsmith RE, McAdams AJ, Larsen PR, MacKenzie M, Hess EV. 1973 Familial autoimmune thyroiditis: maternal-fetal relationship and the role of generalized autoimmunity. J Clin Endocrinol Metab. 37:265-275.

8. Brown RS, Bellisario RL, Mitchell E, Keating P, Botero D. 1993 Detection of thyrotropin binding inhibitory activity in neonatal blood spots. J Clin Endocrinol Metab. 77:1005-1008.

9. Southgate K, Creagh F, Teece M, Kingswood C, Smith BR. 1984 A receptor assay for the measurement of TSH receptor antibodies in unextracted serum. Clin Endocrinol (Oxf). 20:539-543.

10. Kasagi K, Konishi J, lida Y, et al. 1987 A sensitive and practical assay for thyroid-stimulating antibodies using FRTL-5 thyroid cells. Acta Endocrinol (Copenh). 115:30-36.

11. Fort P, Lifshitz F, Pugliese M, Klein I. 1988 Neonatal thyroid disease: differential expression in three successive offspring. J Clin Endocrinol Metab. 66:645-647.

12. Inomata H, Tsuyusaki T, Sasaki N, Tamaru K, Niimi H, Nakajima H. 1988 A patient with Graves' disease who developed hypothyroidism associated with thyroid stimulation blocking immunoglobulin during anti-thyroid drug therapy. Endocrinol Ipn. 35:379-384.

13. Takasu N, Yamada T, Sato A, et al. 1990 Graves' disease following hypothyroidism due to Hashimoto's disease: studies of eight cases. Clin Endocrinol (Oxf). 33:687-698.

14. Zakarija M, Garcia A, McKenzie JM. 1985 Studies on multiple thyroid cell membrane-directed antibodies in Graves' disease. I Clin Invest. 76:1885-1891.

15. Inomata H, Sasaki N, Tamaru K, Ushiku H, Niimi H, Nakajima H. 1986 Relationship between potency of blocking type thyrotropin-binding inhibitor immunoglobulin in three women with primary myxedema and thyroid function of their neonates. Endocrinol Jpn. 33:353-359.

16. Matsuura N, Konishi J, Harada S, et al. 1989 The prediction of thyroid function in infants born to mothers with chronic thyroiditis. Endocrinol Jpn. 36:865-871.

17. McKenzie JM, Zakarija M. 1992 Fetal and neonatal hyperthyroidism and hypothyroidism due to maternal TSH receptor antibodies. Thyroid. 2:155-159.

18. Brown RS, Keating P, Mitchell E. 1990 Maternal thyroid-blocking immunoglobulins in congenital hypothyroidism. J Clin Endocrinol Metab. 70:13411346 . 